\title{
弾性棒を備えた回転体の動的安定性*
}

\author{
大塚 芳 臣*1, 陣 内 靖 介*2 \\ 長田隆*2, 井上昌信*2
}

\section{Dynamic Stability of a Rotor Equipped with Flexible Cantilever Beams}

\author{
Yoshiomi OHTSUKA*3, Yasusuke JINNOUCHI, \\ Takashi NAGATA and Masanobu INOUE \\ ${ }^{* 3}$ Department of Mechanical Engineering, Nishinippon Institute of Technology, \\ 1633 Aratsu, Kanda cho,Miyako-gun, Fukuoka, 800-0394 Japan
}

\begin{abstract}
There is a possibility that a rotor equipped with slender pendulums and flexible booms exposes a risk of its intense self-excited whirling and its attitude instability in a certain region of rotation speed. In previous paper we analyzed and experimented dynamic stability of a translation whirling motion of a rotor equipped with cantilever beams. We obtained the following conclusions by neglecting of an effect of centrifugal force acting on the beam. The system can become unstable when a rotational speed of an axis is nearly equal to a sum of the critical speed of a rotor without beams and the first mode natural frequency of a beam. Any higher mode vibration of a beam does not cause a self-excited vibration in the system. A mode of vibration of a beam changes under centrifugal force when the rotor is rotating. In this paper we investigated the natural mode under the force and how the change of the mode exert an influence on instability of the system, by using the Galerkin method and the Order $\mathrm{N}$ method developed by one of the authors. It was found that even the unstable region of the system, which is simply derived from the neglect of an effect of the centrifugal force, is accurate enough for practical purposes.
\end{abstract}

Key Words: Vibration of Rotating Body, Vibration of Continuous System, Stability, Self-Excited Vibration, Rotor Containing Movable Masses, Flexible Cantilever Beam, Order N Algorithm

\section{1.はじめに}

長い振り子や弾性ブームを取付けた回転体は，液体 を内蔵する中空回転体系と同様に，ある回転数域で激 しい自励ふれまわりや姿勢不安定を引起こす危険性が ある。この事例としては, soft in-plane ロー夕を持つ ヘリコプタ特有の地上共振や空中共振がよく知られて いる(1).これは数秒のうちに機体を破壊し得る非常に 危険な自励振動である。試料保持容器を回転軸にピン 支持した，いわゆる Swing Arm 形の遠心分離機(2)や 振り子を利用した自動平衡装置 ${ }^{(3)}$ でも同種の自励振 動が起きる．弾性ブームによる回転体の姿勢不安定の 例は米国初の人工衛星 Explorer I のアンテナによる 予期に反した短軸まわりの回転がある. 最近でも 1995 年に打上げられた細長い弾性ブームを持ち, 長軸 まわりに定回転するカナダのテザー衛星 ODEPUS-C のスピン不安定が報告された ${ }^{(4)}$.

著者らは，液体内蔵回転軸系 ${ }^{(5)}$, 物理振り子を備え た回転軸系 ${ }^{(2)(3)}$, 環状空洞内に転動球を入れた回転軸

* 原稿受付 2000 年 6 月 14 H.

*1 正員, 西月本工業大学 (\$ 800-0394 福岡県京都郡范田町新 津 1633).

*2 正員, 九州工業大学(画804-0015 北九州市戸畑区仙水 1-1).

E-mail: ootuka@mec.nishitech.ac.jp
系(6) など可動質量を有する回転軸系の動的安定性に ついての研究を行った．回転体のこの種の自励振動は 回転軸の擾乱的なふれまわりがブームや振り子等の可 動質量の振動を誘起し，それによって発生した不釣合 い力が軸のふれまわりを成長・持続させるという正帰 還的力学構造によって引起こされると考えられる.

風力発電用の風車やへリコプタの stiff in-plane 一タは長い弾性ブームを備えた回転体と考えてよい. これらの不安定振動事例の報告はまだ見当たらない が, 地球環境保全の面からも発電用風車の普及と高性 能化が期待される今日，この種の系の動的安定性にお ける解明は学術的にも意義があると思われる。

以上のような背景から, 先に片持ばりを備えた回転 軸のふれまわりの並進モードの動的安定性について, ロータが回転する場合の遠心力によるはりの効果を無 視した解析と実験を行い次の結論を得た(7). 系が不安 定となるのは，はりを除いたロータの危険速度とはり の 1 次固有振動数との和にほぼ等しい領域である.は りの 2 次以上の高次振動モードは系に自励振動を引起 こさない.

本研究では，はりのモードは遠心力によっても変化 するから, Galerkin 法による解析と著者の一人が開 発したOrder $N$ 法 ${ }^{(8)} に よ る$ 数値計算を行い, 遠心力 
が作用する場合のはりの固有モードとそのモード変化 が系の不安定にどのように影響するか検討した。

遠心力が作用する場合のはりの 1 次モードを遠心力 が作用しない場合のはりの 1 次から 3 次基準関数の 1 次結合で表し解析した結果, 系の不安定領域の予測に 対し，遠心力の影響を無視した簡便な方法(7)でも実用 上十分な精度で予測することができることを示した。

\section{おもな記 号}

$A_{0}:$ 口ー夕振幅

$c:$ ロー夕の減衰係数

$c_{1}:$ 片持ばりの単位質量当たりの減衰係数

$E I ：$ 片持ばりの曲げ剛性

$f_{r}(x)$ : 遠心力が作用しない場合の片持ばりの $r$ 次 基準関数

$I_{0}:$ ロータの重心まわりの慣性モーメント

$I_{i}: i_{Z}$ は片持ばりの微小部分 $d m$ を薄板と考え たとき， $X, Y$ 平面に垂直な $Z$ 方向まわりの 回転半径 $=m i_{Z}^{2}$

$k:$ 系のば权定数

$l:$ 片持ばりの長さ

$M:$ 系の全質量 $=M_{0}+n m$

$M_{0}, m:$ ロータと片持ばりの質量

$n$ :片持ばりの個数

$\mathrm{O}-X Y:$ 系の静止座標

$\mathrm{O}_{i}-x_{i} y_{i}$ : たわみのない状態で片持ばりの中立軸に固 定された動座標系

$q ：$ 軸に固定された動座標系から見たロー夕の相 対角速度 $=\omega-\Omega$

$R:$ ロー夕半径

$X, Y:$ 口多変位の $X, Y$ 成分

$u_{s}(x)$ : 遠心力が作用する場合の片持ばりの $s$ 次基 準関数

$y_{i}: i$ 番めの片持ばりのたわみ

$\beta_{r}$ : 遠心力が作用しない場合の片持ばりの $r$ 次 モードの固有振動数

$\gamma_{i}: i$ 番めの片持ばりの取付位置 $=2 \pi(i-1) / n$ $\lambda_{s}$ : 遠心力が作用する場合の片持ばりの $s$ 次モ

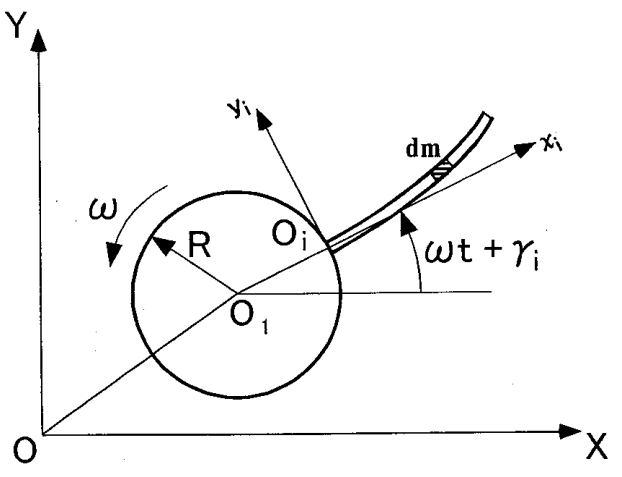

Fig. 1 System to be analyzed

一ドの固有振動数

$\Omega:$ 系の円振動数

$\Omega_{0}$ : 片持ばりを排除したロータの固有円振動数 $\rho A$ : 片持ばりの単位長さ当たりの質量

$\omega:$ ロー夕軸の角速度

$\omega_{1}$ : 不安定領域に扔けるロー夕朝の中心的角速度

\section{2. 理 論 解 析}

$2 \cdot 1$ 系の運動方程式＼cjkstart断面が一様な片持ばりを 複数個取付けたロー夕が並進モードでふれまわってい る場合を考える。解析て使用した座標系を図 1 亿示す。

$\mathrm{O}-X Y$ は静止座標系, $\mathrm{O}_{i}-x_{i} y_{i}$ はたわみのない状態 で片持ばりの中立軸に固定された動座標系である。図 1 に示すようにロー夕は一定の角速度 $\omega$ で軸回転しな がら，静止点 $\mathrm{O}$ を心に水平面上を，変位 $X, Y$ でふ れまわっている。ロー夕の質量は $M_{0}$, 重心まわりの 慣性モーメントは $I_{0}$ である.

ロー夕には長さ $l$ の $n$ 個の片持ばりが円周上に等 間隔に取付けられ，ロータの回転平面内の夕振動す る. 各はりの質量, 密度, 断面積はそれぞれ $m, \rho, A$ である。

ロー夕に不釣合いはなく、ばね線形とする。また， ロータとはりの変位は小さく，はりのたわみによる回 転慣性の項は無視した。

運動エネルギー $T$, ポテンシャルエネルギー $V$, 散 逸関数 $F$ は次の上うに表される.

$$
\begin{aligned}
& T=\frac{1}{2} M_{0}\left(\dot{X}^{2}+\dot{Y}^{2}\right)+\frac{1}{2} I_{0} \omega^{2}+\frac{n}{2} I_{i} \omega^{2}+\sum_{i=1}^{n} \frac{\rho A}{2} \int_{0}^{1}\left[\dot{X}^{2}+\dot{Y}^{2}+\left\{\omega\left(R+x_{i}\right)+\frac{\partial y_{i}}{\partial t}\right\}^{2}+\omega^{2} y_{i}^{2}\right. \\
& -2 \dot{X}\left\{\left[\omega\left(R+x_{i}\right)+\frac{\partial y_{i}}{\partial t}\right] \sin \left(\omega t+\gamma_{i}\right)+\omega y_{i} \cos \left(\omega t+\gamma_{i}\right)\right\}+2 \dot{Y}\left\{\left[\omega\left(R+x_{i}\right)+\frac{\partial y_{i}}{\partial t}\right] \cos \left(\omega t+\gamma_{i}\right)\right. \\
& \left.-\omega y_{i} \sin \left(\omega t+\gamma_{i}\right)\right\}-\omega^{2}\left(R+x_{i}\right) \int_{0}^{x_{i}}\left(\frac{\partial y_{i}}{\partial \xi}\right)^{2} d \xi \rrbracket d x_{i} \\
& V=\frac{1}{2} k\left(X^{2}+Y^{2}\right)+\frac{1}{2} \sum_{i=1}^{n} \int_{0}^{l} E I\left(\frac{\partial^{2} y_{i}}{\partial x_{i}^{2}}\right)^{2} d x_{i}
\end{aligned}
$$




$$
F=\frac{1}{2} c\left(\dot{X}^{2}+\dot{Y}^{2}\right)+\frac{1}{2} c_{1} \sum_{i=1}^{n} \rho A \int_{0}^{l}\left(\frac{\partial y_{i}}{\partial t}\right)^{2} d x_{i}
$$

ただし，運動エネルギー $T$ の最後の項ははりのたわみによるはり要素の回転軸への接近効果を考慮した運動エネ ルギーの補正項であり，その $x_{i}$ に関する被積分関数ははりの単位長さ当たりの遠心力の仮想仕事から求めたもの に等しい. 簡単のため, 今後 $x_{i}$ を $x$, 微分演算子 $\partial / \partial x$ を記号「'」で表す.

Hamilton の原理より, 系の運動方程式はロータの変位とはりのたわみが小さいとし 2 次以上の微小量を無視す ると次のように導加る。

$$
\begin{aligned}
& M \ddot{X}+c \dot{X}+k X=\sum_{i=1}^{n} \rho A \int_{0}^{l}\left\{\left(\ddot{y}_{i}-\omega^{2} y_{i}\right) \sin \left(\omega t+\gamma_{i}\right)+2 \omega \dot{y}_{i} \cos \left(\omega t+\gamma_{i}\right)\right\} d x \\
& M \ddot{Y}+c \dot{Y}+k Y=\sum_{i=1}^{n} \rho A \int_{0}^{l}\left\{-\left(\ddot{y}_{i}-\omega^{2} y_{i}\right) \cos \left(\omega t+\gamma_{i}\right)+2 \omega \dot{y}_{i} \sin \left(\omega t+\gamma_{i}\right)\right\} d x \\
& \ddot{y}_{i}+c_{1} \dot{y}_{i}-\omega^{2} y_{i}+\frac{E I}{\rho A} y_{i}^{\prime \prime \prime \prime}-\frac{1}{2} \omega^{2}\left[\left\{(R+l)^{2}-(R+x)^{2}\right\} y_{i}^{\prime}\right]^{\prime}=\ddot{X} \sin \left(\omega t+\gamma_{i}\right)-\ddot{Y} \cos \left(\omega t+\gamma_{i}\right) \\
& (i=1,2, \cdots, n)
\end{aligned}
$$

ただし， $y_{i}(t, x)$ は次の境界条件を満足する。

$$
y_{i}(t, 0)=y_{i}^{\prime}(t, 0)=y_{i}^{\prime \prime}(t, l)=y_{i}^{\prime \prime \prime}(t, l)=0 \cdots(7)
$$

ロータが回転し遠心力が作用する場合の自由振動で はりの $s$ 次の基準振動 $y_{i}$ を

$$
y_{i}(t, x)=u_{s}(x) \sin \lambda_{s} t
$$

と置き，はりの運動方程式 (6)の同次方程式に代入す ると遠心力が作用する場合のはりの $s$ 次基準関数 $u_{s}(x)$ に関する次の方程式が導かれる。ただし， $\lambda_{s}$ は $s$ 次固有振動数である.

$$
\begin{aligned}
& \frac{E I}{\rho A} u_{s}^{\prime \prime \prime \prime}-\frac{1}{2} \omega^{2}\left[\left\{(R+l)^{2}-(R+x)^{2}\right\} u_{s}^{\prime}\right]^{\prime} \\
& \quad-\left(\lambda_{s}^{2}+\omega^{2}\right) u_{s}=0 \\
& u_{s}(0)=u_{s}^{\prime}(0)=u_{s}^{\prime \prime}(l)=u_{s}^{\prime \prime \prime}(l)=0 \\
& \quad(s=1,2, \cdots, \infty) \quad \ldots \ldots \ldots \ldots \ldots \ldots \ldots \ldots \ldots \ldots \ldots \ldots \ldots \ldots \ldots \\
&
\end{aligned}
$$

また，式(8)の第 1 式に $u_{r}$ を掛けた式と第 1 式で $s=r$ と置き $u_{s}$ を掛けた式をそれぞれ差引いて，0か ら $l$ まで積分し，3回の部分積分を行い，境界条件の 第 2 式を用いれば次の関係式が導かれる。

$$
\left(\lambda_{s}^{2}-\lambda_{r}^{2}\right) \int_{0}^{\ell} u_{s} u_{r} d x=0 \quad(s \neq r)
$$

上式より，遠心力が作用しない場合のはりの基準関数 と同様，ロータが回転し遠心力の作用を受ける基準関 数は直交関係を満たす。

\section{$2 \cdot 2$ はりの固有振動数と固有モード}

2・2・1 Galerkin 法による解析 ロータが回転 し, 遠心力の影響を受けるはりの $s$ 次基準関数 $u_{s}$ を 求めるために，遠心力が作用しない場合のはりの $r$ 次 の基準関数 $f_{r}$ を導入する. $u_{s}$ を $f_{r}$ の 1 次結合の形

$$
u_{s}(x)=\sum_{r=1}^{N} a_{r} f_{r}(x)
$$

で表すと Galerkin 法によりモード振幅 $a_{r}$ に関する 次の連立 1 次同次方程式を得る。

$$
\left(\lambda_{s}^{2}-\beta_{s}^{2}+\omega^{2}\right) a_{s}-\sum_{r=1}^{N} \frac{F_{s r}}{2 \bar{D}_{s}} \omega^{2} a_{r}=0
$$

$$
\begin{aligned}
(s & =1,2, \cdots, N) \\
D_{s} & =\int_{0}^{l} f_{s}^{2} d x \\
F_{s r} & =\int_{0}^{l}\left\{(R+l)^{2}-(R+x)^{2}\right\} f_{s}^{\prime} f_{r}^{\prime} d x
\end{aligned}
$$

ただし， $\beta_{r}$ は遠心力が作用していないときのはりの $r$ 次固有振動数で, $f_{r}$ と $\beta_{r}$ は次のような条件を満足 する.

$$
\begin{aligned}
& \frac{E I}{\rho A} f_{r}^{\prime \prime \prime \prime}=\beta_{r}^{2} f_{r} \quad(r=1,2, \cdots, \infty) \\
& f_{r}(0)=f_{r}^{\prime}(0)=f_{r}^{\prime \prime}(l)=f_{r}^{\prime \prime \prime}(l)=0
\end{aligned}
$$

自明でない解を得るには, 式(10)より

$$
\left|\boldsymbol{B}-\lambda_{s}^{2} \boldsymbol{E}\right|=\mathbf{0}
$$

を満足しなければならない。ただし， $\boldsymbol{E}$ は単位行列,

$$
\begin{aligned}
& \boldsymbol{B}=\left[\begin{array}{cccc}
b_{11} & b_{12} & \cdots & b_{1 N} \\
b_{21} & b_{22} & \cdots & b_{2 N} \\
\vdots & \vdots & \ddots & \vdots \\
b_{N 1} & b_{N 2} & \cdots & b_{N N}
\end{array}\right] \\
& b_{s r}= \begin{cases}\frac{F_{s r}}{2 D_{s}} \omega^{2} & (s \neq r) \\
\left(\frac{F_{s s}}{2 D_{s}}-1\right) \omega^{2}+\beta_{s}^{2} & (s=r)\end{cases}
\end{aligned}
$$

これは行列 $\boldsymbol{B}$ に関する固有值問題に帰する。このと き，モード振幅 $a_{r}(r=1,2, \cdots, N)$ は固有べクトルで 表されるから, 遠心力が作用しているときの基準関数 us 求めることができる.

遠心力が作用しているときの $s$ 次固有振動数 $\lambda_{s}$ は, その固有值より求めることができるが, $F_{s r}(s \neq r)$ は $F_{s s}$ に比較して非常に小さいので $F_{s r}$ を無視すれば, 軸回転数 $\omega$ が極端に大きくないとき $\lambda_{s}$ は近似的に次 のように表すことができる。

$$
\lambda_{s} \cong \sqrt{\left(\frac{F_{s s}}{2 D_{s}}-1\right) \omega^{2}+\beta_{s}^{2}} \quad(s=1,2, \cdots, N)
$$


ロータが回転し遠心力の作用を受けるはりの 1 次基 準関数 $u$ を遠心力が作用しない場合の 1 次から 3 次 モードの基準関数 $f_{1}, f_{2}, f_{3}$ の 1 次結合で近似したと き, 式(12)より得られたはりの 1 次固有振動数 $\lambda_{1}$ 抒 よびモード振幅 $a_{1}, a_{2}, a_{3}$ と軸回転数 $\omega$ の関係を図 2 の実線に示す。計算に使用した数值は文献 $(7)$ の実験 条件と同じ値を用いた。その条件と実験装置の概略を 表 1 と図 3 に示す.

遠心力が作用する場合のはりの 1 次基準関数 $u_{1}$ は 遠心力が作用しない場合の高次モード $f_{2}, f_{3}$ の影響を 含むが，その量ははりの長いところでモード振幅 $a_{1}$ に対し $a_{2}$ で約 14\%， $a_{3}$ で約 5\%とかなり小さい。は りの 1 次固有振動数 $\lambda_{1}$ は軸の回転が速くなるとほぼ それに比例して増加する。

ロータが回転し，遠心力を受けるはりの 1 次基準関 数 $u_{1}$ を図 4 に示す. 軸の角速度が上がるにつれて $u_{1}$ は一定の形に近づく。

Table 1 Experiment condition

\begin{tabular}{|l|l|}
\hline Mass of rotor $\mathrm{M}_{0}$ & $756 \mathrm{~g}$ \\
\hline Hub radius of rotor $\mathrm{R}$ & $40 \mathrm{~mm}$ \\
\hline Critical speed of rotor $\Omega_{0}$ & $1.8 \mathrm{~Hz}$ \\
\hline Density of beam $\rho$ & $4.58 \mathrm{~g} / \mathrm{cm}^{3}$ \\
\hline Area of cross section of beam A & $3.14 \mathrm{~mm}^{2}$ \\
\hline Young's modulus of beam E & $360 \mathrm{~N} / \mathrm{mm}^{2}$ \\
\hline Second moment of area of beam I & $0.785 \mathrm{~mm}^{4}$ \\
\hline Number of beam $\mathrm{n}$ & 4 \\
\hline
\end{tabular}
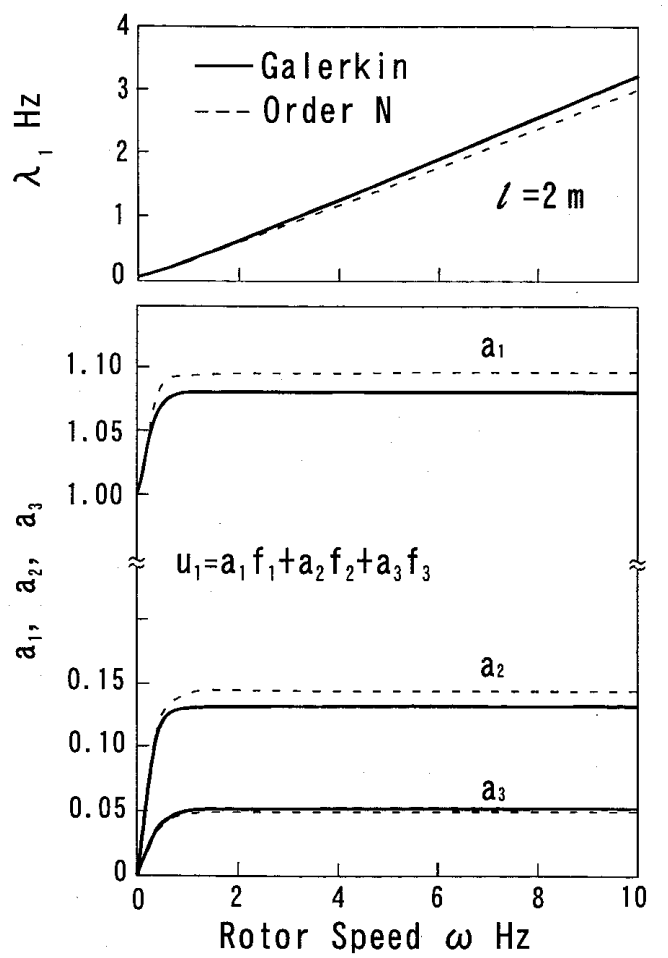

Fig. 2 First natural frequency and mode amplitude of beam attached to rotating rotor $\mathbf{2 \cdot 2 \cdot 2}$ Order N 法による数値計算 Galerkin 法 では，遠心力の作用を受ける片持ばりの 1 次モードを 遠心力の作用を受けない片持ばりの基準関数の線形結 合で近似した，遠心力の作用を受けるはりのモードを より忠実に表現できる Order $\mathrm{N}$ 法 ${ }^{(8)}$ と比較検討する。 Order $\mathrm{N}$ 法は, 運動学や動力学の漸化的記述と加速度 項に関して陽な運動方程式が直接得られるという特徵 を有し,変形されたd'Alembert の原理に基づいて定 式化された効率のよい手法である。

一般にシステムの自由度を $N$ とすれば $N^{3}$ のオー ダの計算量を要するが, Order $\mathrm{N}$ 法は $N$ のオーダで 計算することができ, システムを表す関数 $\left(M_{i}, \bar{G}_{i}\right.$, $\left.\boldsymbol{P}_{i}^{u}, \boldsymbol{P}_{i}^{c}, \bar{p}_{i}^{c}, i=1,2, \cdots, N\right)$ をユーザが定義するだけで 解析できる。ただし， $\boldsymbol{M}_{i}$ は質量マトリックス， $\bar{G}_{i}$ は 力の総計べクトル, $\boldsymbol{P}_{i}^{u}, \boldsymbol{P}_{i}^{c}, \bar{p}_{i}^{c}$ はシステムの拘束を表 す行列とべクトルである。

本計算でははりを $n_{b}$ 個に分割し，各要素は図 5 に 示すように二つの剛体から成り, 左端から $\xi_{0}$ のとこ ろで回転ばねとピンで連結されている， $l_{i}$ は要素の長 さ, $\theta_{i}^{L}, \theta_{i}^{R}$ は静止座標から見た二つの剛体の回転角で,

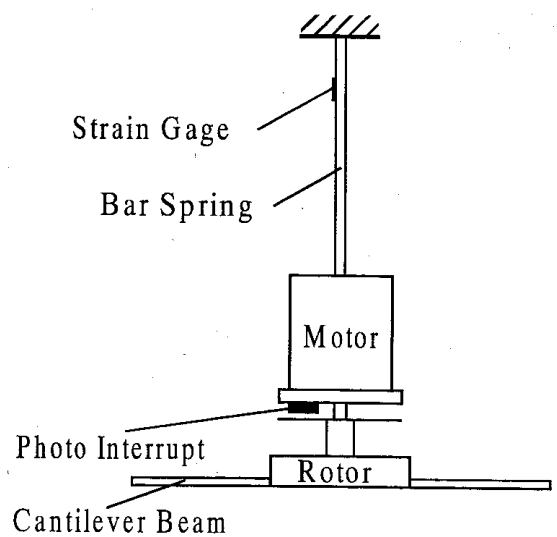

Fig. 3 Experiment apparatus

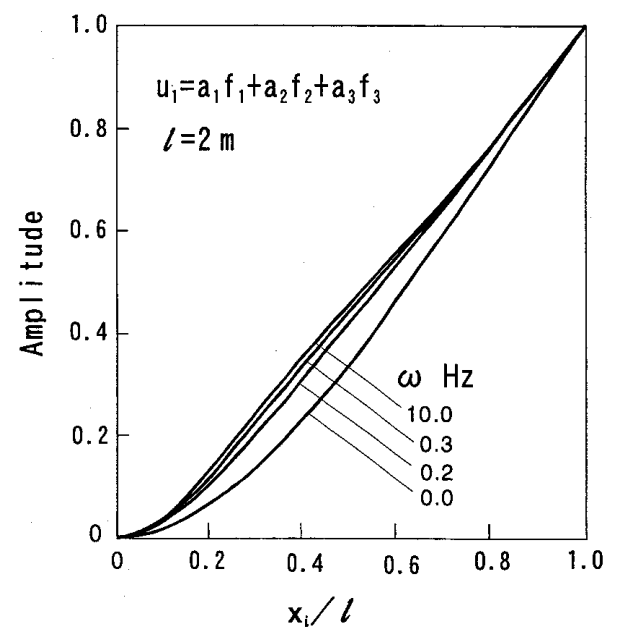

Fig. 4 First mode of beam attached to rotating rotor 
$\Delta \theta_{i}=\theta_{i}^{R}-\theta_{i}^{L}$ である. $\Delta \delta_{i}$ は右部先端の $y_{i}$ 方向の変 位, $M_{i}^{L}, M_{i}^{R}$ 注要素の両端に作用する曲げモーメント である。このとき片持ばりの関係から

$$
\Delta \theta_{i}=\frac{M_{i}^{R} l_{i}}{E I}, \quad \Delta \delta_{i}=\frac{M_{i}^{R} l_{i}^{2}}{2 E I}
$$

また, 図 5 から

$$
\Delta \delta_{i}=\left(1-\eta_{0}\right) l_{i} \sin \Delta \theta_{i}
$$

ただし， $\eta_{0}=\xi_{0} / l_{i}$ 。したがって，式(14)，(15)より

$$
\eta_{0}=1-\frac{\Delta \theta_{i}}{2 \sin \Delta \theta_{i}}
$$

すなわち， $\Delta \theta_{i}$ が小さいときヒンジの位置 $\eta_{0} \cong 1 / 2$ で ある。

ロータの軸を原点 $\mathrm{O}$ に固定しふれまわりのない状 態で, 軸回転のみ行った場合の数值計算で得られたは りのたわみから，最小二乗法によりモード振幅 $a_{1}, a_{2}$, $a_{3}$ を求めた結果を図 2 の破線に示す。これらのモー ド振幅よりロータが回転し遠心力の作用を受ける場合 の 1 次基準関数 $\iota_{1}$ は図 4 の実線とほとんど一致する ため区別できない。これらの図に示すように, Order $\mathrm{N}$ 法による数值計算結果と Galerkin 法による解析結 果を比較するとよく一致している.

最小二乗法では関数の積分が必要となるが, Simp sonの公式を用いて数值積分を行った. はりの分割数 $n_{b}$ は，口ー夕静止時の遠心力が作用しない場合の基 準関数 $f_{1}(x)$ の結果がこれ以上分割数を増やしてもさ ほど影響を与えない数 $n_{b}=14$ とした。

$2 \cdot 3$ 系の振動数方程式と不安定領域 図 6 に示 すように, ロータが振幅 $A_{0}$, 振動数 $\Omega$ で小さな調和 振動するとき

$$
X=A_{0} \cos \Omega t, \quad Y=A_{0} \sin \Omega t
$$

粘性の項を無視すれば系の運動方程式 (4)から（6)は 次のように書き直すことができる.

$$
\begin{gathered}
A_{0}\left(k-\Omega^{2} M\right) \cos \Omega t=\sum_{i=1}^{n} \rho A \int_{0}^{l}\left\{\left(\ddot{y}_{i}-\omega^{2} y_{i}\right)\right. \\
\left.\times \sin \left(\omega t+\gamma_{i}\right)+2 \omega \dot{y}_{i} \cos \left(\omega t+\gamma_{i}\right)\right\} d x
\end{gathered}
$$

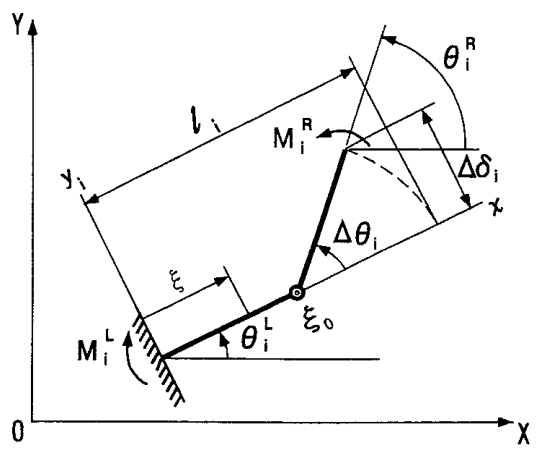

Fig. 5 Element of beam

$$
\begin{aligned}
& A_{0}\left(k-\Omega^{2} M\right) \sin \Omega t=\sum_{i=1}^{n} \rho A \int_{0}^{t}\left\{-\left(\ddot{y}_{i}-\omega^{2} y_{i}\right)\right. \\
& \left.\times \cos \left(\omega t+\gamma_{i}\right)+2 \omega \dot{y}_{i} \sin \left(\omega t+\gamma_{i}\right)\right\} d x
\end{aligned}
$$

$$
\begin{aligned}
& \ddot{y}_{i}-\omega^{2} y_{i}+\frac{E I}{\rho A} y_{i}^{\prime \prime \prime \prime}-\frac{1}{2} \omega^{2}\left[\left\{(R+l)^{2}\right.\right. \\
& \left.\left.-(R+x)^{2}\right\} y_{i}^{\prime}\right]^{\prime}=-A_{0} \Omega^{2} \sin \left(q t+\gamma_{i}\right) \\
& (i=1,2, \cdots, n)
\end{aligned}
$$

ただし， $q=\omega-\Omega$ である. 先に求めた遠心力が作用 するときの $s$ 次基準関数 $u_{s}$ を用いて，はりの運動方 程式(19)に $y_{i}=d_{s} A_{0} u_{s}(x) \sin \left(q t+\gamma_{i}\right)$ を代入し Galerkin 法を用いると次の方程式を得る。

$$
\begin{array}{r}
d_{s}\left(\lambda_{s}^{2}-q^{2}\right) \int_{0}^{l} u_{s}^{2} d x+\Omega^{2} \int_{0}^{l} u_{s} d x=0 \\
\quad(s=1,2, \cdots, \infty) \quad \cdots \ldots \ldots \ldots \ldots \ldots \ldots \ldots \ldots \ldots \ldots \ldots
\end{array}
$$

これから

$$
\begin{aligned}
& d_{s}=\frac{\Omega^{2} H_{s}}{\left(q^{2}-\lambda_{s}^{2}\right) G_{s}} \ldots \ldots \ldots \ldots \ldots . . . . . . . \\
& G_{s}=\int_{0}^{l} u_{s}^{2} d x, \quad H_{s}=\int_{0}^{l} u_{s} d x
\end{aligned}
$$

を得る。式(21)を用いてロー夕の運動方程式(17)， (18)に調和バランス法を用いると

$$
\Omega_{0}^{2}-\Omega^{2}=-\frac{\mu \Omega^{4}}{\left(q^{2}-\lambda_{s}^{2}\right)}
$$

ただし，

$$
\Omega_{0}=\sqrt{k / M_{0}}, \quad \mu=\frac{n m H_{s}^{2}}{2 M l G_{s}}
$$

式(22)の左辺は，ロータの慣性力とばね力(ロー夕 力), 右辺はロー夕に作用するはりの慣性力 (はり力) を表す。この式はロータ力とはり力の釣合いを要求す る式であるが, 系の固有振動数 $\Omega$ を与える振動数方 程式でもある. 式(22)は $\Omega$ に関する 4 次方程式で, 解 $\Omega$ がすべて実根ならば系は安定であり，もし共役

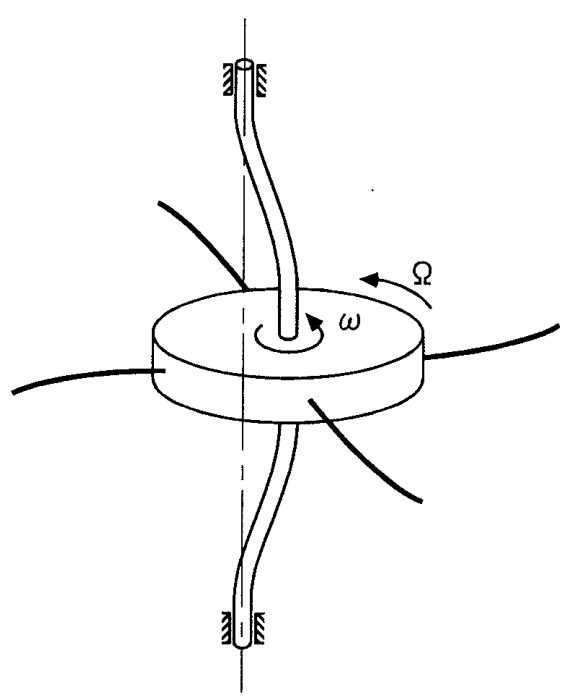

Fig. 6 Motion of rotor and beam in translation mode 
な複素根をもつならば系は不安定となり自励振動が発 生する危険性がある(7).

不安定領域の中心的な軸回転数 $\omega_{1}$ は

$$
\omega_{1} \cong \Omega_{1}+\lambda_{s}
$$

ただし，

$$
\Omega_{1}=\frac{\mu \omega+\sqrt{\mu^{2} \omega^{2}+(1-\mu)\left(\Omega_{0}^{2}+\mu \lambda_{s}^{2}+3 \mu \omega^{2}\right)}}{1-\mu}
$$

$\Omega_{1}$ は高回転数域における系の 1 次固有振動数である. 多くの場合 $\mu \ll 1$ であるから $\Omega_{1} \cong \Omega_{0}$.

軸回転数が高くなるほど $\lambda_{s}$ の值は高くなるから， はりの高次モードの振動に扔いて, 通常安定の十分条 件 $\lambda_{s}>\omega(s \geq 2)$ を満たすから系は安定となる。それゆ え, 系が不安定となる危険性があるのははりの1次振 動モードのみであると考えられる.したがって, 式 (23) は次のように書き直される.

$$
\omega_{1} \cong \Omega_{0}+\lambda_{1}
$$

すなわち，軸回転数がはりを排除したロー夕の危険速 度 $\Omega_{0}$ と遠心力の作用を受けるはりの 1 次固有振動数 $\lambda_{1}$ との和にほ等しくなる領域で系は不安定となる.

図 7 に系の不安定領域を示す．実線で挟まれた部分 は方程式(22)から得られた不安定領域，すなわち遠心 力が作用する場合のはりの 1 次基準関数 $u_{1}$ を遠心力 が作用しない場合の基準関数 $f_{1}, f_{2}, f_{3}$ の 1 次結合で表 して得られた不安定領域である。一点鎖線は式(24) か ら得られた不安定領域の中心的な軸回転数を示す。

破線で挟まれた部分と I 印は， $u_{1}$ を $f_{1}$ のみで表し た場合の不安定領域と実験で求めた不安定領域をそれ ぞれ示す(7). 跀は Order N 法により運動方程式 (4) 〜 (6)をシミュレーションして得られた場合の不安定 領域を表す。

実線部と破線部を比較すると，不安定領域にほとん ど差はない，後者の場合はりが長いところで約 $6 \%$ 不 安定領域が狭くなっている程度である。この理由は $2 \cdot 2 \cdot 1$ 項で述べたように, $u_{1}$ の近似に関するモード振 幅 $a_{2}, a_{3}$ の影響は $a_{1}$ に比べて小さく，不安定領域の 決定に直接関係する係数 $H_{s}, G_{s}$ はそれぞれ積分と二 乗されることにより求められるから $a_{2}, a_{3}$ の影響がさ らに小さくなるためである。したがって $f_{1}$ のみで近 似した 精度で不安定領域を予測することができる。

実線部は実験抢よび Order $\mathrm{N}$ 法の結果と比較的よ く一致している.

\section{3. 結 論}

柔軟な片持ばりを備えた回転軸のふれまわりの並進

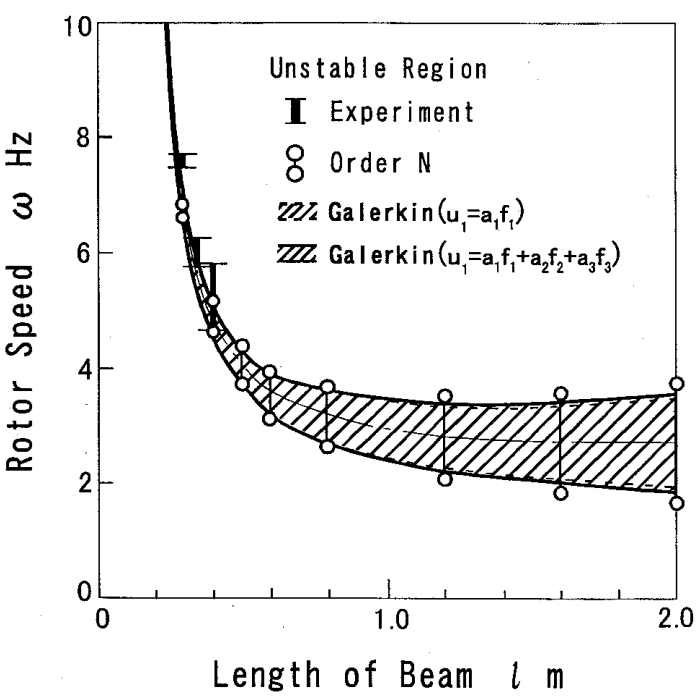

Fig. 7 Unstable region of system

モードの動的安定性について, 遠心力が作用する場合 のはりの 1 次モードを，遠心力が作用しない場合のは りの 1 次から 3 次の基準関数の 1 次結合で近似した Galerkin 法による解析と Order N 法による数值計算 を行い, はりの固有モードについて検討し, 系の不安 定領域を求めた。解析にあたりロータの変位とはりの たわみは小さいとして，運動方程式の 2 次以上の微小 項とはりのたわみによる回転慣性の項は無視した。そ の結果をまとめると次のようである。

ロータが回転し，遠心力が作用する場合のはりの 1 次固有振動数とそのモードは Galerkin 法による解と Order N 法による数値解においてよく一致した。

遠心力が作用する場合のはりの 1 次モードを，遠心 力が作用しない場合のはりの 1 次基準関数のみで近似 した簡便な方法でも，はりの長い場合系の不安定領域 をわずかに狭く評価するが，実用上十分な精度で不安 定領域を予測することができる。

\section{文献}

（1）加藤筧一郎・今永勇生，ヘリコプタ入門，(1989)，192 196, 東京大学出版会.

（2）陣内靖介・ほ加2名, 機論, 65-632，C (1999)，1346 1351.

(3) Kubo, S., ほか 3 名, Bull. JSME, 29-249(1986), 924-928.

(4) Vigneron, F. R., ほか3 名, J. Spacecraft Rockets, 34-5 (1997), 662-669.

(5) Jinnouchi, Y., ほか3 名, Trans. ASME, J. Press. Vessel Technol., 111(1989), 450-456.

（6）井上順吉 - ほ加 3 名, 機論, 45-394, C (1979)，646-652.

(7) Jinnouchi, Y., ほか 3 名, Proc. of APVC'95, Vol. 1.2 (1995), 486-491.

(8) Nagata, T., "Dynamics of Flexible Multibody System: A Formulation with Applications", Ph. D. Thesis, (1995), 14-51, 182-194, The University of Tokyo. 